\title{
COMPARISON OF ANALGESIC EFFICACY OF INTRATHECAL KETOROLAC, MORPHINE AND ITS COMBINATION AS AN ADJUVANT TO BUPIVACAINE FOR LOWER LIMB SURGERIES- A PROSPECTIVE RANDOMISED STUDY
}

\author{
Syed Uwais Raza1, Jyothi B2, Pratishruti³, Safiya Imtiaz Shaikh4 \\ ${ }^{1}$ Assistant Professor, Department of Anaesthesia, Deccan College of Medical Sciences, Hyderabad. \\ ${ }^{2}$ Associate Professor, Department of Anaesthesia, KIMS, Hubli. \\ ${ }^{3}$ Postgraduate Student, Department of Anaesthesia, KIMS, Hubli. \\ ${ }^{4}$ Professor, Department of Anaesthesia, KIMS, Hubli.
}

\begin{abstract}
BACKGROUND
ABSTRACT

Ketorolac is a non-steroidal anti-inflammatory agent with strong analgesic activity, when added as an adjuvant to intrathecal bupivacaine acts on the COX receptors at the spinal level and inhibits the synthesis of prostaglandins.

Aims- To evaluate the analgesic efficacy of intrathecal ketorolac, morphine and its combination when added as an adjunct to bupivacaine and, onset of sensory and motor blockade, quality of analgesia, side effects of the adjuvants used intrathecally.
\end{abstract}

\section{MATERIALS AND METHODS}

A prospective, randomised, double blind, placebo controlled study was conducted on 100 adult patients undergoing elective lower limb orthopaedic and general surgeries. Patients were randomly allocated into 4 groups $(n=25)$ by using computer generated

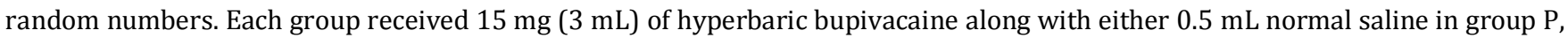
ketorolac $2 \mathrm{mg}(0.5 \mathrm{~mL})$ in group $\mathrm{K}$, morphine $200 \mathrm{mcg}(0.5 \mathrm{~mL})$ in group $\mathrm{M}$, and ketorolac-morphine combination $2 \mathrm{mg}+200 \mathrm{mcg}$ $(0.5 \mathrm{~mL})$ in group KM. Statistical analysis of data was done by using statistical package for social science (SPSS) evaluation version 22. One way ANOVA, Kruskal-Wallis tests were used for multiple group comparison and categorical data analysed by chi-square test.

\section{RESULTS}

The mean visual analogue scale score in group $\mathrm{P}$ was $5.4 \pm 1.8$ and in groups $\mathrm{M}, \mathrm{K}$, KM were $5.3 \pm 1.5,5.1 \pm 1.7,5.3 \pm 1.6$ respectively. The duration of analgesia in group P was $136 \pm 16 \mathrm{~min}$. and in groups $\mathrm{M}, \mathrm{K}$, and KM were $695 \pm 62 \mathrm{~min}$., $590 \pm 56 \mathrm{~min}$., and $1188 \pm 93 \mathrm{~min}$ respectively. The quality of analgesia was excellent at $92 \%$ in combination group compared to other groups.

\section{CONCLUSION}

Ketorolac-morphine combination as an adjunct to intrathecal bupivacaine provides prolonged post-operative analgesia compared to ketorolac or morphine alone that is up to 15 hours in lower limb surgeries with significant inflammation.

\section{KEYWORDS}

Bupivacaine, Ketorolac, Morphine, Anaesthesia, Spinal, Postoperative Pain, Inflammation.

HOW TO CITE THIS ARTICLE: Raza SU, Jyothi B, Pratishruti, et al. Comparison of analgesic efficacy of intrathecal ketorolac, morphine and its combination as an adjuvant to bupivacaine for lower limb surgeries- A prospective randomised study. J. Evolution Med. Dent. Sci. 2018;7(02):171-175, DOI: 10.14260/jemds/2018/38

\section{BACKGROUND}

Ketorolac is a potent non-steroidal anti-inflammatory drug, has been shown to have antinociceptive effects when administered intrathecally both in laboratory animals and humans.[1] Preclinical studies suggest major site of action of ketorolac is the spinal cord and is not neurotoxic.[2] Intrathecal ketorolac responds better in pain conditions associated with significant inflammation.[3] Post-operative analgesia is important in perioperative care. A method of post-operative analgesia, which requires minimum technical intervention and expertise and gives good quality analgesia which is safe and easily available is very valuable.

'Financial or Other Competing Interest': None.

Submission 20-11-2017, Peer Review 24-12-2017,

Acceptance 30-12-2017, Published 08-01-2018.

Corresponding Author:

Dr. Jyothi B,

Associate Professor,

Department of Anaesthesia,

KIMS, Hubli, Karnataka.

E-mail:driyothib1@gmail.com

DOI: $10.14260 /$ jemds/2018/38

\section{(c) (i) $(9)$}

Drugs which are cost effective with least side effects and with good patient and surgeon acceptance is the need of the hour today. Spinal anaesthesia with bupivacaine is a common analgesic technique in lower abdomen and lower limb surgeries. A single intrathecal injection of bupivacaine provides analgesia only for 2.5 hours to 3 hours. Various adjuvants to intrathecal local anaesthetics such as opioids, clonidine, ketamine, neostigmine ${ }^{[4]}$ have been used to prolong postoperative analgesia. Intrathecal ketorolac does not produce serious adverse events. ${ }^{[2]}$ This study was conducted to evaluate and compare the analgesic efficacy and side effects between intrathecal ketorolac, intrathecal morphine and combination of ketorolac and morphine when added as an adjunct to bupivacaine for post-operative pain relief in lower limb inflammatory orthopaedic and general surgeries. Our primary objective was to determine the duration of analgesia, secondary objective was to evaluate the onset of sensory and motor blockade, quality of analgesia, s adjuvants used intrathecally.

\section{MATERIALS AND METHODS}

A prospective, double blind, placebo controlled randomised clinical study was conducted for a period of 1 year (January 
2014- December 2014) on 100 adult patients, undergoing various elective lower limb procedures (orthopaedic and general surgery) under subarachnoid block at our hospital. The approval of institutional ethical committee was obtained. Age group of 18-60 yrs., patient who gave informed consent, American Society of Anesthesiologists (ASA) physical status I and II, were included in the study. Patients with medical complications like coagulopathies, disease and deformity of spine, with contraindication for non-steroidal antiinflammatory drugs (NSAIDS) or opioids, history of hypersensitivity to the study drugs were excluded from the study. Sample size was calculated for one way ANOVA design, to analyse duration of analgesia in four groups $(\mathrm{P}, \mathrm{K}, \mathrm{M}, \mathrm{KM})$ as the primary outcome measure is based on the findings from Gabriela et al study, the effect size considered was 0.4 and with alpha error of $5 \%$, power of $80 \%$, the minimum sample size required in each group is 19 and the total sample size is 76 . So sample size was rounded off to 25 in each group, making a total of 100 . The sample size was calculated using $G$ power software version 3.1.5.[5,6]

Pre-anaesthetic evaluation was done to all patients under inclusion criteria. Premedicated with tablet diazepam $10 \mathrm{mg}$ orally night before surgery. Basic laboratory investigations were done. Electrocardiogram (ECG) was advised in patients more than 40 years of age and chest x-ray when indicated. Patient's height and weight was noted. The entire procedure of spinal anaesthesia was explained to the patient. Patients were explained about visual analogue scale (VAS) and were taught how to express the degree of pain on the scale.

Patients were randomly allocated into four groups, by computer generated random numbers. Each group consists of 25 patients. All patients received total drug volume of $3.5 \mathrm{~mL}$ with any one of the drug solution as shown in Table 1.

The study drug solution was prepared in coded syringes by anaesthesiologist not taking part in the study and was given by another anaesthetist who is also not taking part in the study. Thus, the patient and observer were blinded in the study. Ampoule containing preservative free ketorolac tromethamine $30 \mathrm{mg}$ in $1 \mathrm{~mL}$ (Intas pharmaceuticals limited) or preservative free morphine $10 \mathrm{mg}$ in $1 \mathrm{~mL}$ (Troikaa pharmaceuticals) was used along with $0.5 \%$ hyperbaric bupivacaine (Neon laboratories limited). The dose of intrathecal ketorolac and morphine was measured by using insulin syringe.

In the operating room (OR), routine monitors like noninvasive blood pressure (NIBP), pulse oximetry, ECG were connected. Baseline vital parameters were noted. Peripheral intravenous (IV) line was secured with 18G cannula. Ringer lactate solution $10 \mathrm{~mL} / \mathrm{kg}$ infused IV before initiation of spinal anaesthesia. Under aseptic preparation, lumbar puncture was performed at L3-L4 position in sitting or lateral position by midline approach after the local infiltration with $2 \%$ lignocaine, $3.5 \mathrm{~mL}$ of solution prepared (Table 1) was injected into the subarachnoid space and patient was made to lie in the supine position.

Time of intrathecal injection noted. Loss of sensation noted with light touch using cotton swabs and degree of motor block assessed by modified Bromage Scale. Inj. ephedrine $5 \mathrm{mg}$ or inj. mephentermine $6 \mathrm{mg}$ intravenously given to treat arterial hypotension [fall of systolic blood pressure (SBP) $>20 \%$ from the baseline] and inj. Atropine
(0.6 mg) administered intravenously to treat pulse rate below 55 beats per minute (bpm). Respiratory depression (respiratory rate $<10$ breaths per minute) noted. Pulse rate, blood pressure, respiratory rate were monitored every $5 \mathrm{~min}$ for the first $15 \mathrm{~min}$, then every $15 \mathrm{~min}$ for $1 \mathrm{hr}, 30 \mathrm{~min}$ for the next $2^{\text {nd }} \mathrm{hr}, 3^{\text {rd }} \mathrm{hr}$, every $1 \mathrm{hr}$ from $4^{\text {th }}, 5^{\text {th }}, 6^{\text {th }} \mathrm{hr}$ after which at $12^{\text {th }}$ and $24^{\text {th }} \mathrm{hr}$ throughout intra operative and postoperative period. Side effects like pruritus, nausea, vomiting, urinary retention (non-catheterised patients) and sedation were monitored throughout procedure and post operatively for $24 \mathrm{hrs}$.

\section{The following Parameters were noted-}

a. Time of intrathecal injection

b. Time of onset of sensory block [i.e. time taken from intrathecal injection of drug to time to complete loss of sensation to light touch with cotton swabs to T10].

c. Incidence of hypotension, bradycardia and sedation level was assessed.

d. Duration of analgesia [measured from the time of intrathecal injection to the first request of analgesia with VAS $>4$ ] was monitored.

e. Pain intensity was assessed by visual analogue scale.

f. Incidence of side effects like epigastric pain, nausea, vomiting, urinary retention, itching were monitored

g. Sedation was monitored by Campbell scoring.[7] 1-Wide awake, 2-Sedated but easily arousable, 3Drowsy and difficult to arouse, 4-Unarousable.

\section{Nausea \& Vomiting}

0-No symptom, 1-Symptom present but treatment not required, 2- Symptoms present \& treatment given.

Pruritis - Four-point ordinal scale.

0-None, 1-Mild, 2-Moderate, 3-Severe.

Pain was assessed by visual analogue scale (VAS) at the time of first pain medication, patient was given a scale marked from 0-10 and was asked to mark on a scale the degree of pain he or she experienced ranging from "No" pain at 0 to "Maximum "pain at 10. In patients with $\mathrm{VAS}>4$, rescue analgesic was given with Inj. Diclofenac $75 \mathrm{mg}$ intramuscular (IM) and study concluded. At the end of the study, the patient was asked about the effectiveness of intrathecal drug with respect to pain relief. Depending on the subjective response, quality of analgesia was assessed, noted and compared according to Table 2. All the observations and particulars of each patient were recorded in a proforma and the patient belonging to the study group was disclosed after 24 hours postoperatively.

Statistical analysis of data was done by using statistical package for social science (SPSS) evaluation version 22 . Results were expressed as mean, standard deviation. Frequencies expressed as number and percentage. One way ANOVA, Kruskal-Wallis test used for multiple group comparison and categorical data analysed by chi-square test. $\mathrm{P}$ - value of 0.05 or less is considered for statistical significance. The characteristics of the four groups were comparable in terms of age, height, weight, ASA classification, gender, and duration of surgery (Table 3 ). The mean onset of sensory block at T10 in groups $\mathrm{K}, \mathrm{M}, \mathrm{KM}$ and P were $3.12 \pm$ $1.24 \mathrm{~min}, 2.36 \pm 0.81 \mathrm{~min}, 2.12 \pm 0.67 \mathrm{~min}$, and $3.68 \pm 1.11$ min. respectively. The time of onset of sensory block in KM 
and $\mathrm{M}$ group was shorter than $\mathrm{K}$ and $\mathrm{P}$ group. The groups $\mathrm{K}$ versus $K M, K$ versus $M, K M$ versus $P$, and $M$ versus $P$ were statistically significant with earlier onset of sensory block compared to $K$ versus $P$ and $K M$ versus $M$. (Table 4 \& Graph 1). The mean onset of motor block in groups $\mathrm{K}, \mathrm{M}, \mathrm{KM}$ and $\mathrm{P}$ were $2.92 \pm 0.70 \mathrm{~min}, 3.36 \pm 0.71 \mathrm{~min}, 3.48 \pm 0.65 \mathrm{~min}$., and $3.96 \pm 0.61 \mathrm{~min}$. respectively. In the study, the duration of analgesia was considered from the time of intrathecal injection to time of first rescue analgesia. The statistical analysis showed that the duration to first request of analgesia in group $\mathrm{K}, \mathrm{KM}, \mathrm{M}$ is significantly longer when compared to group $\mathrm{P}$. Between groups $\mathrm{KM}$ versus $\mathrm{K}, \mathrm{KM}$ versus $\mathrm{M}, \mathrm{KM}$ versus $P$ duration of analgesia was significantly longer in $K M$ group. Wherein $K$ versus $P, K$ versus $M$, and $M$ versus $P$, the difference in duration of analgesia was statistically significant. In our study, the pain intensity was measured by visual analogue score at first pain medication. Statistical analysis shows that there is no significant difference in VAS score between all the groups and results are comparable. (Table 4 \& Graph 1).

With respect to quality of analgesia, statistical analysis showed that patients in group KM, M and K had good-toexcellent quality of pain relief when compared to group $\mathrm{P}$ who had poor to satisfactory pain relief. (Graph 4).

Incidence of headache was more with $\mathrm{K}$ group $16 \%$, nausea and vomiting was seen in $12 \%$ of patients in $\mathrm{M}$ group. Bradycardia (4\%), shivering (8\%) was seen in group $\mathrm{P}$ and group $\mathrm{M}$ respectively. There was no incidence of pruritus or respiratory depression in any of the four groups. (Graph 5) However, sedation never exceeded grade 2 (drowsy). (Graph 2).

\begin{tabular}{|c|}
\hline Group Drugs \\
\hline GROUP-K (ketorolac) $3 \mathrm{~mL}$ of $15 \mathrm{mg}$ of heavy bupivacaine + \\
$0.5 \mathrm{~mL}$ of $2 \mathrm{mg}$ ketorolac \\
GROUP-M (morphine) $3 \mathrm{~mL}$ of $15 \mathrm{mg}$ of heavy bupivacaine + \\
$0.5 \mathrm{~mL}$ of $200 \mu \mathrm{g}$ morphine \\
GROUP-KM (ketorolac + morphine) $3 \mathrm{~mL}$ of $15 \mathrm{mg}$ of heavy \\
bupivacaine $+0.25 \mathrm{~mL}$ of $2 \mathrm{mg}$ of ketorolac and $0.25 \mathrm{~mL}$ of \\
$200 \mu \mathrm{g}$ of morphine \\
GROUP-P (placebo) $3 \mathrm{~mL}$ of $15 \mathrm{mg}$ of heavy bupivacaine + \\
$0.5 \mathrm{~mL} 0.9 \%$ normal saline \\
*K- Ketorolac, †M- Morphine, $\neq$ KM- Ketorolac and Morphine, \\
§P- Placebo \\
\hline Table 1. Group Distribution
\end{tabular}

\begin{tabular}{|c|c|}
\hline Pain Score & Pain Relief \\
\hline 1 & Excellent \\
\hline 2 & Good \\
\hline 3 & Satisfactory \\
\hline 4 & Poor \\
\hline Table 2. Quality of Analgesia \\
\hline
\end{tabular}

\begin{tabular}{|c|c|c|c|c|}
\hline Variables & $\begin{array}{c}\text { Group } \\
\mathbf{K} \\
(\mathbf{n = 2 5})\end{array}$ & $\begin{array}{c}\text { Group } \\
\mathbf{M} \\
(\mathbf{n = 2 5})\end{array}$ & $\begin{array}{c}\text { Group } \\
\mathbf{K M} \\
(\mathbf{n = 2 5})\end{array}$ & $\begin{array}{c}\text { Group } \\
\mathbf{P} \\
(\mathbf{n = 2 5})\end{array}$ \\
\hline \multirow{2}{*}{ Age (years) } & $40.24 \pm$ & 34.56 & $38.64 \pm$ & $36.96 \pm$ \\
& 16.12 & \pm 10.69 & 15.53 & 10.59 \\
\hline \multirow{2}{*}{ Weight $(\mathrm{kg})$} & $57.96 \pm$ & $58.00 \pm$ & $60.04 \pm$ & $57.36 \pm$ \\
& 6.79 & 5.62 & 6.74 & 5.66 \\
\hline \multirow{2}{*}{ Height (cm) } & $164.52 \pm$ & $163.6 \pm$ & $162.12 \pm$ & $163.28 \pm$ \\
& 6.80 & 5.33 & 5.37 & 5.68 \\
\hline ASA grade I/II & $11 / 14$ & $14 / 11$ & $15 / 10$ & $9 / 16$ \\
\hline Male/female & $15 / 10$ & $16 / 9$ & $15 / 10$ & $14 / 11$ \\
\hline
\end{tabular}

\begin{tabular}{|c|c|c|c|c|}
\hline $\begin{array}{c}\text { Duration of } \\
\text { surgery (min.) }\end{array}$ & $\begin{array}{c}74.40 \pm \\
29.68\end{array}$ & $\begin{array}{c}77.72 \pm \\
27.25\end{array}$ & $\begin{array}{c}76.68 \pm \\
24.70\end{array}$ & $\begin{array}{c}76.20 \pm \\
24.54\end{array}$ \\
\hline \multicolumn{3}{|c|}{ Values in the table are mean \pm SD or absolute numbers. } \\
SD = Standard deviation, ${ }^{*}$ ASA - American society of \\
Anesthesiologists, †Yrs- years, † Kg- Kilograms, \\
§ Cm- Centimetres, \ Min.- Minutes. \\
Table 3. Demographic Chart
\end{tabular}

\begin{tabular}{|c|c|c|c|c|}
\hline Variables & $\begin{array}{c}\text { Group } \\
K \\
(n=25)\end{array}$ & $\begin{array}{c}\text { Group } \\
M \\
(n=25)\end{array}$ & $\begin{array}{c}\text { Group } \\
\text { KM } \\
(n=25)\end{array}$ & $\begin{array}{c}\text { Group } \\
\text { P } \\
(n=25)\end{array}$ \\
\hline $\begin{array}{c}\text { Time of onset of } \\
\text { sensory block } \\
\text { (min.) }\end{array}$ & $\begin{array}{c}3.12 \pm \\
1.24\end{array}$ & $\begin{array}{c}2.36 \pm \\
0.81\end{array}$ & $\begin{array}{c}2.12 \pm \\
0.67\end{array}$ & $\begin{array}{c}3.68 \pm \\
1.11\end{array}$ \\
\hline $\begin{array}{l}\text { Time of onset } \\
\text { of motor block } \\
\text { (min.) }\end{array}$ & $\begin{array}{c}2.92 \pm \\
0.70\end{array}$ & $\begin{array}{c}3.36 \pm \\
0.71\end{array}$ & $\begin{array}{c}3.48 \pm \\
0.65\end{array}$ & $\begin{array}{c}3.96 \pm \\
0.61\end{array}$ \\
\hline $\begin{array}{c}\text { Highest } \\
\text { dermatome } \\
\text { level of } \\
\text { sensory block }\end{array}$ & $\mathrm{T} 10$ & $\mathrm{~T} 10$ & $\mathrm{~T} 10$ & $\mathrm{~T} 10$ \\
\hline $\begin{array}{l}\text { Time of first } \\
\text { analgesic } \\
\text { request (min.) }\end{array}$ & $\begin{array}{c}590.20 \pm 56 \\
87\end{array}$ & $\begin{array}{c}695.40 \pm 6 \\
2.21\end{array}$ & $\begin{array}{c}1188.40 \pm 9 \\
3.58\end{array}$ & $\begin{array}{l}136.60 \\
\pm 16.85\end{array}$ \\
\hline
\end{tabular}

Values in the table are mean \pm standard deviation or absolute numbers (percentage). All times are calculated from time of intrathecal injection. *T- thoracic dermatome, †min.- minutes.

Table 4. The Mean onset of Sensory Block at T10 Level in Groups $K, M$, KM and $P$

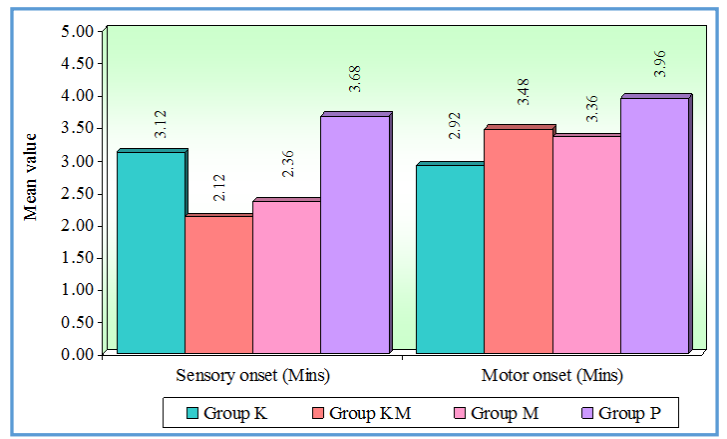

Graph 1: Comparison of Four Groups (K, KM, M, P) with Respect to Sensory and Motor Onset (minutes)

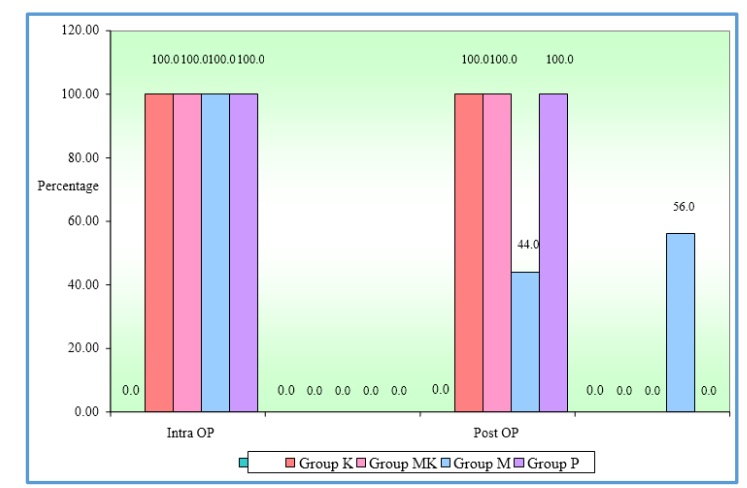

Graph 2. Comparison of Four Groups (K, MK, M, P) with Respect to Intraoperative and Postoperative Sedation Score 


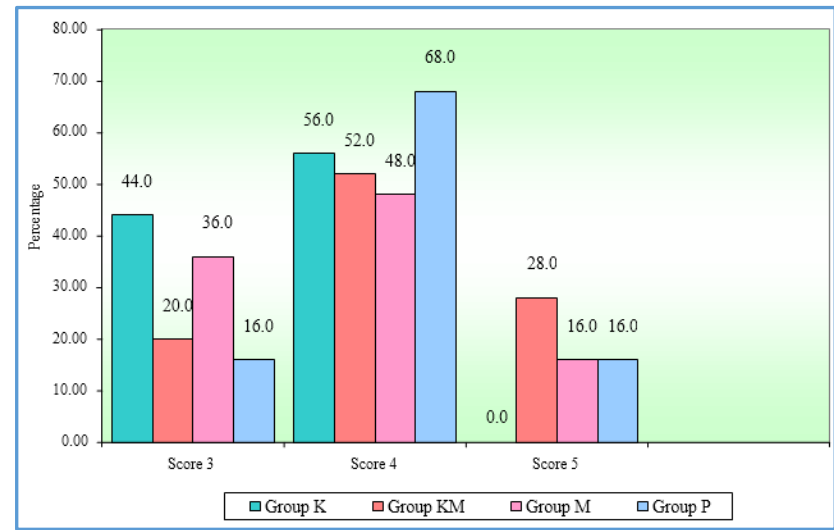

Graph 3. Comparison of Four Groups (K, MK, M, P) with Respect to VAS Score (at Time of Rescue Analgesia)

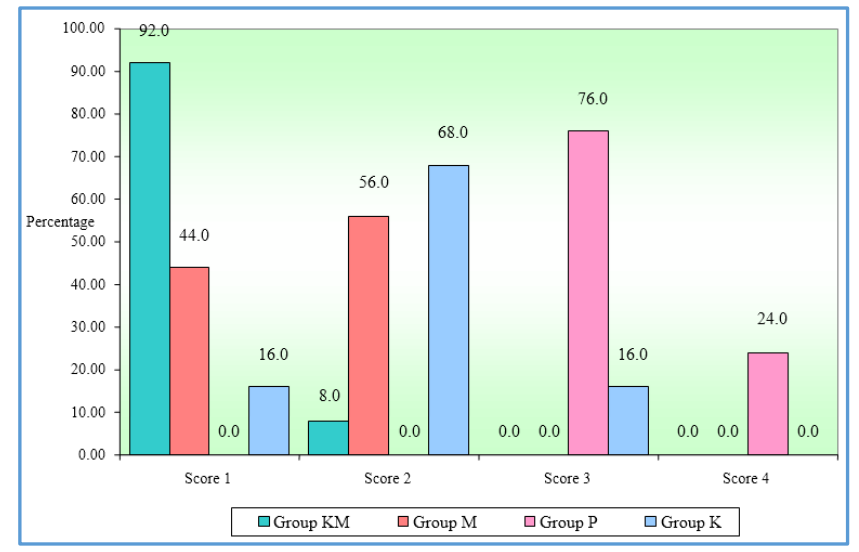

Graph 4. Comparison of Four Groups (K, MK, M, P) with Respect to Quality of Analgesia Score.

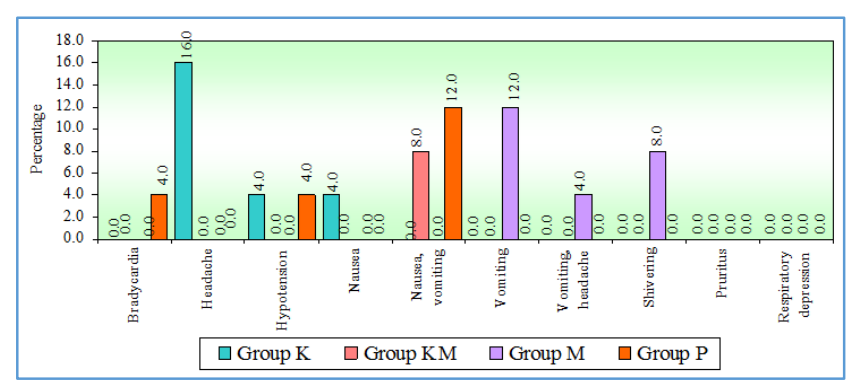

Graph 5. Side Effects of Four Groups

\section{DISCUSSION}

Ketorolac is a potent nonsteroidal anti-inflammatory drug that has been shown to have antinociceptive effects when administered intrathecally both in laboratory animals and humans.[1] The dose of ketorolac used in the present study corresponds to that of James C. Eisenach et al.[2]

Spinal morphine analgesia is mediated by $\mu 2$-opioid receptors. Morphine, which is a hydrophilic opioid, has a longer residence time in the cerebrospinal fluid and therefore has long-lasting analgesia with intrathecal injection. $[4,8]$ In our study, we compared efficacy and adverse effects of intrathecal ketorolac, intrathecal morphine, combination of both and normal saline with bupivacaine in lower limb inflammatory orthopaedic and general surgeries. The patients studied across the group did not vary much with respect to age, sex, weight, height and ASA grading. The types of surgeries performed and the duration were almost comparable in the four groups.

In our study, the mean onset time of motor blockade is rapid in $\mathrm{K}$ group compared to other groups and rest of the three groups are comparable to each other (Graph 1). Whereas the study conducted by Lauretti et al[1] did not show any significant difference in the onset of the motor block between the groups.

The four groups did not show any statistical difference in the level of sensory blockade, $\chi 2=15.85$ with a p value $>$ 0.05 . (Graph 1). A study conducted by Lauretti et al[1] also did not show any difference in the level of sensory blockade between the four groups. In our study, there was no significant haemodynamic and respiratory parameter changes[3] correlating well with studies conducted by Lauretti et al,[1] James C. Eisenach et al.[2,9] Patients who received bupivacaine with ketorolac-morphine combination had significantly longer duration for first request of analgesia almost double when compared to ketorolac and morphine alone groups with $\mathrm{p}$ value $<0.001$ which is statistically highly significant. Similar corroborative results were obtained by Lauretti et al[1] in 80 patients undergoing orthopaedic knee surgery with similar four groups, where the mean duration of postoperative analgesia in $\mathrm{M}$ group was $440 \pm 38 \mathrm{~min}$., $\mathrm{K}$ group was $381 \pm 44 \mathrm{~min}$., MK group was $926 \pm 222$ min. compared to control group $C$ was $170 \pm$ $13 \mathrm{~min}$. The results confirm the analgesic efficacy of intrathecal ketorolac, morphine, and its combination as an adjunct in prolonging the postoperative analgesia.

Pain intensity was assessed by visual analogue scale. In the present study, VAS score of 4 is most commonly seen in all four groups with the highest frequency in control group P. As the $\mathrm{p}$ value is $0.0594(>0.05)$, there was no statistical significance among the four groups. Comparable results to this were also found in the study conducted by Lauretti et al [1], where the mean VAS scores (in $\mathrm{cm}$ ) at first rescue analgesic $5.4 \pm 1.8,5.3 \pm 1.5,5.1 \pm 1.7,5.3 \pm 1.6$ in groups $C$, M, K and MK respectively. (Graph 3).

Quality of analgesia in our study- group P had poor to satisfactory pain relief, Groups K, M, KM had good-toexcellent pain relief. Statistical analysis showed that there is significant increase in quality of pain relief with ketorolac, morphine, and combination groups when compared to control group P. Thus, to conclude, the quality of analgesia was best in the combination group and worse in control group. (Graph 4).

Nausea alone was seen in 1 patient in group $\mathrm{K}$ and Nausea and vomiting was seen in 2 patients in KM group and 3 patients in group P. None of the patients had either nausea or nausea with vomiting in other groups. Vomiting was noted in $3(12 \%)$ patients in group $\mathrm{M}$ and no other groups had vomiting. Shivering was noted in $2(8 \%)$ patients in group $\mathrm{M}$ and no other group had shivering. Headache was noted in $4(16 \%)$ patients in group K. Patients in no other groups had headache. Bradycardia was noted in 1 (4\%) patient in group $\mathrm{P}$ which was transient and reverted back to normal without any intervention. Patients in no other groups had bradycardia. Hypotension was noted in 1 (4\%) patient in each group $\mathrm{K}$ and $\mathrm{P}$ and it necessitated administration of fluid and vasopressors for a variable period for maintenance of BP. (Graph 5). None of the patient had grade $3^{\text {rd }}$ or $4^{\text {th }}$ level sedation. (Graph 2). None of the 
patients had urinary retention, pruritus, respiratory depression, epigastric pain, or neurological deficits. All side effects noted were minimal.

Similar results were seen in the study conducted by Lauretti et al,[1] where there were minimal side effects and no significant complications.

Limitations of our study: The reason for enhancement of onset of sensory blockade and motor blockade in ketorolac-morphine combination group and ketorolac group respectively is not known and there are no supporting literatures available. More studies are required on intrathecal ketorolac as an adjuvant to bupivacaine in humans for evaluation of analgesic efficacy in different surgical procedures.

\section{CONCLUSION}

Intrathecal ketorolac-morphine combination as an adjunct to bupivacaine provides prolonged analgesia, superior pain relief and good haemodynamic stability with minimal side effects in patients with significant inflammatory limb procedures when compared to ketorolac or morphine alone as an adjuvant to intrathecal bupivacaine.

\section{REFERENCES}

[1] Lauretti GR, Righeti CCF, Mattos AL. Intrathecal ketorolac enhances intrathecal morphine analgesia following total knee arthroplasty. J Anaesthesiol Clin Pharmacol 2013;29(4):503-8.
[2] Eisenach JC, Curry R, Hood DD, et al. Phase I safety assessment of intrathecal ketorolac. Pain 2002;99(3):599-604.

[3] Stuart P. Novel additives to neuraxial blockade. South Afr J Anaesth Analg 2011;17(1):86-9.

[4] Rathmell JP, Lair TR, Nauman B. The role of intrathecal drugs in the treatment of acute pain. Anesth Analg 2005;101(Suppl 5):S30-43.

[5] Faul F, Erdfelder E, Lang AG, et al. G*Power 3: a flexible statistical power analysis program for the social, behavioral and biomedical sciences. Behavioral Research Methods 2007;39(2):175-91.

[6] Faul F, Erdelfer E, Buchner A, et al. A statistical power analyses using $\mathrm{G}^{*}$ Power 3.1: tests for correlation and regression analyses. Behavior Research Methods 2009;41(4):1149-60.

[7] Hiralchavda, Purvi JM, Arun HV. A comparative study of intrathecal fentanyl and sufentanil with bupivacaine heavy for postoperative analgesia. The Internet Journal of Anesthesiology 2009;20(2).

[8] Ummenhofer WC, Arends RH, Shen DD, et al. Comparative spinal distribution and clearance kinetics of intrathecally administered morphine, fentanyl, alfentanil and sufentanil. Anesthesiology 2000;92(3):739-53.

[9] Eisenach JC, Curry R, Tong C, et al. Effects of intrathecal ketorolac on human experimental pain. Anesthesiology 2010;112(5):1216-24. 